\title{
A computational fluid dynamics modeling study of guide walls for downstream fish passage
}

Kevin Brian Mulligan ${ }^{\mathrm{a}, \mathrm{d} *}$, Brett Towler ${ }^{\mathrm{b}}$, Alex Haro ${ }^{\mathrm{c}}$, David P. Ahlfeld ${ }^{\mathrm{a}}$

${ }^{a}$ University of Massachusetts Amherst, 130 Natural Resources Rd., 18 Marston Hall, Amherst, MA 01003, USA

${ }^{\mathrm{b}}$ U.S. Fish \& Wildlife Service, Northeast Region, 300 Westgate Center Dr., Hadley, MA 01035, USA

${ }^{c}$ U.S. Geological Survey, Leetown Science Center, S.O. Conte Anadromous Fish Research Laboratory, 1 Migratory Way, Turners Falls, MA 01376, USA

${ }^{\mathrm{d}}$ Present address: U.S. Geological Survey, Leetown Science Center, S.O. Conte Anadromous Fish Research Laboratory, 1 Migratory Way, Turners Falls, MA 01376, USA

*Corresponding Author

E-mail addresses: kmulligan@usgs.gov (K.B. Mulligan), brett_towler@fws.gov (B. Towler), aharo@usgs.gov (A. Haro), ahlfeld@engin.umass.edu (D.P. Ahlfeld)

\begin{abstract}
A partial-depth, impermeable guidance structure (or guide wall) for downstream fish passage is typically constructed as a series of panels attached to a floating boom and anchored across a water body (e.g. river channel, reservoir, or power canal). The downstream terminus of the wall is generally located nearby to a fish bypass structure. If guidance is successful, the fish will avoid entrainment in a dangerous intake structure (i.e. turbine intakes) while passing from the headpond to the tailwater of a hydroelectric facility through a safer passage route (i.e. the bypass). The goal of this study is to determine the combination of guide wall design parameters that will most likely increase the chance of surface-oriented fish being successfully guided to the bypass. To evaluate the flow field immediately upstream of a guide wall, a parameterized computational fluid dynamics model of an idealized power canal was constructed in $\odot$ ANSYS Fluent v 14.5 (ANSYS Inc., 2012). The design parameters investigated were the angle and depth of the guide wall and the average approach velocity in the power canal. Results call attention to the importance of the downward to sweeping flow ratio and demonstrate how a change in guide wall depth and angle can affect this important hydraulic cue to out-migrating fish. The key findings indicate that a guide wall set at a small angle $\left(15^{\circ}\right.$ is the minimum in this study) and deep enough such that sweeping flow dominant conditions prevail within the expected vertical distribution of fish approaching the structure will produce hydraulic conditions that are more likely to result in effective passage.
\end{abstract}

Keywords: Guide wall, fish passage, downstream, computational fluid dynamics 


\section{Introduction}

Many fish species have evolved to use different types of environments over their life span in order to enhance the population's chance of survival. Each selected environment is well suited for a particular part of the life cycle for the fish (McDowall, 1997). For instance, anadromous clupeids (genus Alosa) are born in a fresh water river system where there are fewer predators, migrate as juveniles to the ocean where there is a more abundant food supply, then migrate as adults back to the fresh water river to spawn, completing the life cycle (Weiss-Glanz et al., 1986). In addition, potamodromous fish perform migrations for the purposes of both feeding and spawning, but only within fresh water river systems. Without the ability to freely move between and within each aquatic ecosystem, the chance of a fish population's long-term survival is greatly diminished (Limburg and Waldman, 2009; McDowall, 1987).

As a result of anthropogenic development on river systems, full and partial barriers to fish movement commonly exist in watersheds worldwide (Williams et al., 2012). These barriers typically consist of small to large size dams, culverts, and other structures. Despite substantial efforts, issues related to passage of fish both up and downstream of dams are not yet fully resolved (Bunt et al., 2012; Enders et al., 2009). Even if a fishway structure is in place, poor design, predation, and degraded water quality can lead to fatigue, injury, fatality, or other hindrances to fish survival.

At a typical hydropower facility there are three primary routes of downstream passage. The three routes, ordered by typical proportion of average annual river flow, are 1) through the turbine intakes, 2) over a spillway and 3) through a fish bypass (often constructed as a sluice gate, weir, or pipe). The downstream bypass is typically constructed in close proximity to the turbine intakes to reduce the number of fish passing through the turbines. The challenge is to 
either induce behaviorally or actively guide the fish into the bypass rather than the turbine intakes, which the bulk of the flow in the power canal passes through (typically $>90 \%$ when there is no spilling over the dam). Guidance technologies (e.g., louvers, racks, screens, perforate plates, guide walls) are designed for this purpose.

Like other fish passage devices, guidance technologies rely on the rheotactic response of fish (among other factors) to improve downstream passage efficiency and reduce migration delay (Schilt, 2007). Rheotaxis is defined as a fish's behavioral orientation to the water current (Montgomery et al., 1997). A fish's movement with (or against) the water current is referred to as a negative (or positive) rheotaxis, respectively. In the case of a full-depth guidance structure (e.g. louvers and angled bar racks), the vertical velocity component upstream of the guidance structure is ignored and a 2-dimensional velocity vector is often used to inform the design. These two velocity components are referred to as the sweeping velocity (velocity component parallel to the guidance structure pointing in the direction of the bypass) and the normal velocity (velocity component perpendicular to the guidance structure pointing directly at the face of the structure). A guidance structure installed at 45 degrees or less to the upstream flow field will result in a sweeping velocity greater than or equal to the normal velocity, thereby reducing the likelihood of impingement and entrainment. For this reason, guidance technologies are typically set at an angle of 45 degrees or less to the flow field, thus creating a hydraulic cue designed to elicit a negative rheotactic response from migrating fish. This cue encourages their movement downstream towards the bypass.

In the case of a partial-depth guide wall (Fig. 1) that is aimed at guiding surface-oriented fish, a strong downward vertical velocity component may be present upstream of the wall. The vertical velocity component may compete with, or even overwhelm, hydraulic cues created by 
the sweeping and normal velocities. Dominant vertical velocities may encourage vertical fish movement and exacerbate entrainment potential. NextEra Energy Maine Operating Services, LLC (2010), Kock et al. (2012), and Faber et al. (2011) showed instances where a large proportion of downstream migrating fish passed below a guide wall, possibly due to a strong vertical velocity component.

A guide wall is typically constructed of a series of floating partial-depth, impermeable panels. Depending upon the hydroelectric project configuration, the guide wall is anchored across a river channel, reservoir, or power canal (Scott, 2012). Scott (2012) explains that the concept is based on knowledge that: 1) juvenile anadromous fish tend to swim in the top portion of the water column (Whitney et al., 1997; Buckley and Kynard, 1985; Faber et al., 2011), 2) some juvenile species have been shown to select a shallow rather than deep passage route when given the choice (Johnson et al., 1997), and 3) anadromous juveniles tend to migrate downstream in the river thalweg (Whitney et al., 1997). The concept of a floating guide wall may have originated after dam operators observed fish accumulating along debris booms, similar to the booms used for a floating guide wall.

Novel to this study is the examination of the flow field upstream of a guide wall set at a wide range of depths and angles to flow and subject to a wide range of average approach velocities, all within an idealized power canal. New metrics, useful in the evaluation of guide walls, are presented. These metrics aim to explore the range of velocities and the strength of the downward flow signal a fish may encounter while swimming along a guide wall. The goal is to determine the combination of design parameters that will most likely increase the chance of surface-oriented fish being successfully guided to the bypass. This analysis is performed through sophisticated numerical modeling referred to as computational fluid dynamics (CFD). 


\section{Methodology}

To evaluate the flow field immediately upstream of a guide wall, we used a parameterized CFD model of an idealized power canal (ㄷ ANSYS Fluent v 14.5 , 2012). Fluent is a finite-volume code that iteratively solves the conservation of mass and momentum over a set of discretized control volumes within the model domain until convergence is reached. Section 2.1 describes the model domain (or geometry of the model). Section 2.2 introduces the pertinent design parameters and details the range and interval over which each is examined. Section 2.3 defines each of the boundary conditions applied to the model. These are the numerical conditions applied to the perimeter edges and faces of the model domain and must be satisfied within the solution. Section 2.4 describes the mesh of the CFD model. This pertains to the methods used to divide (or discretize) the region within the model domain into a large number of small finite control volumes. Section 2.5 details the solvers (or numerical solution scheme) used to calculate the model results and the convergence criteria applied to the solvers.

\subsection{Model Domain}

Fig. 2 displays the plan view of the power canal and a cross sectional view from the furthest downstream location at the bypass entrance. The section downstream of the guide wall was not modeled to simplify the analysis. To accurately model head losses that are incurred by the structure a more complex model than is presented here is required.

For each scenario, the inlet location was fixed and the approach distance $\ell$ was held constant at $25 \mathrm{ft}$. The longitudinal length of the guide wall, $L$, varies according to the angle of the guidance structure, $\theta$. The canal width, $\mathrm{W}$, was $100 \mathrm{ft}$. and the canal depth, $\mathrm{H}$, was $40 \mathrm{ft}$. The width of the bypass was $0.1 \mathrm{~W}$ or $10 \mathrm{ft}$. The depth of the bypass opening was $0.25 \mathrm{H}$ or $10 \mathrm{ft}$. The total flow through the model inlet, $Q_{T}$, the flow through the bypass outlet, $Q_{B}$, and the flow 
through the main power canal outlet, $Q_{C}$, vary depending upon the average approach velocity, $V$. The percent of the total flow through the bypass, $\mathrm{p}$ (equal to $100^{*} Q_{B} / Q_{T}$ ), for all model runs was $5 \%$. The size of the bypass opening and the percent of the total flow through the bypass (p) are within the typical range for surface flow outlets (Johnson and Dauble, 2006) and p is also within the range of design criteria used by the US Fish and Wildlife Service in the Northeast (Odeh and Orvis, 1998).

\subsection{Model Parameters}

The key parameters relevant to this work are the depth of the guide wall, $d$, the angle of the guide wall, $\theta$, and the average inlet velocity, $V$. There are a total of 40 scenarios. Table 1 displays the ranges and intervals each parameter is evaluated on:

Table 1: Model Parameters

\begin{tabular}{|c|c|c|}
\hline Parameter & Range & Interval \\
\hline Depth of the Guide Wall $(d), \mathrm{ft}$. & 10 to 20 & 3.33 \\
\hline Angle of the Guide Wall $(\theta), \mathrm{deg}$ & 15 to 45 & 7.5 \\
\hline Average Inlet Velocity $(V), \mathrm{ft} / \mathrm{s}$ & 2 to 4 & 2 \\
\hline
\end{tabular}

The range of $d$ was chosen because it represents a set of typical values found within the literature. While guide walls have been set deeper than $20 \mathrm{ft}$., the designs are less common and are intended for use in deeper canals and forebays. The range of $\theta$ is typical for surface guidance technologies and all guide walls referred to in the literature are within this range. The range of $V$ is also typical within a power canal, although $2 \mathrm{ft} / \mathrm{s}$ is more common. A value for $V$ of $4 \mathrm{ft} / \mathrm{s}$ is high for a typical power canal.

\subsection{Boundary Conditions}

Three different types of boundary conditions were used in each of the model scenarios. The first type of boundary condition was a velocity inlet. The inlet was defined using a velocity 
profile characteristic of a fully developed viscous flow with an average inlet velocity, $V$. The velocity profile for $V=2 \mathrm{ft} / \mathrm{s}$ is shown in Fig. 3. To attain each developed flow profile, a rectangular channel CFD model was constructed, termed the Inlet Calculation CFD Model (ICCM). The ICCM used a cross section at the inlet of the Idealized CFD Model and extruded it long enough such that fully developed flow was achieved. In each ICCM run, the inlet was set to a uniform velocity equal to $V$ and the outlet was specified as an outflow carrying $100 \%$ of the flow. Identical solvers, described later, were used for both the ICCM runs and the Idealized CFD Model. The velocity profile at the outlet of the ICCM was used as the velocity profile at the inlet of the Idealized CFD Model. In addition to the velocity profile, the turbulence intensity (defined as the root-mean-square of the turbulent velocity fluctuations divided by the mean velocity) was specified at 5\%. (O) ANSYS Fluent v 14.5 (ANSYS Inc., 2012) recommends the use of 5\% in the event this value is unknown, as it was in this case.

The second type of boundary condition was a pressure outlet. This outlet type is defined in two locations: 1) directly under the guide wall and 2) through an entrance to a bypass. The two white areas in the cross-section A-A for Fig. 2 depicts each of the boundary locations. Each outlet was prescribed a hydrostatic pressure distribution and a target mass flow rate corresponding to the percentage of flow through the bypass, $\mathrm{p}$. The streamlines were converging at the pressure outlet specified below the guide wall; because of this a hydrostatic pressure distribution was not entirely accurate. However, this likely has a minimal impact on the results as the pressure distribution should only be slightly different from hydrostatic. In a physical test performed on a lab-scale model guide wall (unpublished data, Mulligan et al., 2015), the estimated pressure below the wall was essentially hydrostatic. 
The third type of boundary condition was a wall condition with a specified shear and roughness height value. The water surface was defined as a slip-condition with a specified shear stress of zero and zero roughness because shear stress at the water-air interface can be considered negligible. The channel walls and bottom were defined as a no-slip condition, with a defined roughness height of $1.64 \times 10^{-2}$. The face of the guide wall was also defined as a no-slip condition, but the roughness height is $8.20 \times 10^{-2}$. An actual guide wall exterior is often composed of a rubber or stainless steel.

\subsection{Mesh}

In all scenarios for both the Idealized CFD Model and the ICCM, the domains were divided into a number of finite volumes in the form of tetrahedrons. Face and body sizing rules were applied in different regions of the domain. The smallest cells occur near the boundaries and guidance structure. The element face sizing on the guidance wall ranged between 0.8 and $1.6 \mathrm{ft}$. The face sizing on the pressure outlets ranged between 1.0 and $1.6 \mathrm{ft}$. Inflation layers were used to accurately model the wall roughness effects on the flow field. The inflations layers were applied at all boundaries of the model, including the guide wall. The aspect ratio, orthogonal quality, and skewness were the primary metrics used to evaluate mesh quality. Number of finite volumes ranged from approximately 350,000 to 512,000.

\subsection{Solver and Convergence Criteria}

All CFD runs performed in this analysis used the second order upwind method to solve the conservation of momentum equations for steady-state conditions. The runs were solved using the SIMPLE scheme (Patankar and Spalding, 1972) as the pressure-velocity coupling method. The realizable k- $\mathcal{E}$ turbulence closure model with standard wall functions was used to describe the turbulent kinetic energy and turbulent dissipation rate. Similar to momentum, the 
turbulence model was solved using the second order upwind method. However, in all scenarios each model was first solved using the first order upwind scheme. The results of the first order upwind solving scheme were used as the initial solution to the second order upwind solver. This provided a means to reach convergence quicker. Convergence criteria included the equation residuals for continuity, $\mathrm{x}$-velocity, $\mathrm{y}$-velocity, z-velocity, turbulent kinetic energy, and turbulent dissipation rate. Additional monitors included the integral of the velocity magnitude on the outlet below the guide wall, integral of velocity magnitude on the outlet to the bypass, total volume integral of the velocity magnitude in all fluid cells, the integral of the skin friction coefficient on the guidance face, and the total volume integral of turbulent kinetic energy in all fluid cells. Additional details regarding the conservation of momentum and turbulence solvers can be found in the (C) ANSYS Fluent v. 14.5 code documentation manual (ANSYS Inc., 2012).

\section{Results}

To compare the 40 scenarios, several metrics were formulated based on each scenario's velocity output. Section 3.1 examines trends found in the water velocity throughout each scenario and shows in depth results for a single scenario. Section 3.2 introduces a new metric referred to as the Maximum to Mean Velocity Ratio $(M M R)$, considered a possible indicator of fatigue and/or entrainment. Section 3.3 presents the Downward to Sweeping Velocity Ratio $(D S R)$, considered a possible indicator of guidance. Lastly, Section 3.4 introduces the Upper Guidance Zone Depth $\left(d^{*}\left(t^{*}\right)\right)$, a metric based off of a threshold $D S R$ value, $t^{*}$.

\subsection{Velocity Magnitude, Components, and Distribution}

Fig. 4 displays the velocity magnitude and components $(x-y-z)$ on three vertical planes in the $\mathrm{y}-\mathrm{z}$ axis for the scenario where $d=10 \mathrm{ft}, \theta=30^{\circ}$, and $V=2 \mathrm{ft} / \mathrm{s}$. The three planes are at $x=$ $0.25 L, 0.5 L$, and $0.75 L$, where $x$ was equal to 0 at the model inlet (the upstream boundary 
condition). The model boundaries are shown in a sketched image around the contour plots. This figure shows several important points, all of which apply to each of the 40 total scenarios. First, the maximum velocity magnitude occurs immediately below the guide wall, while directly beside the guide wall the water velocity magnitudes tend to be less than the average inlet velocity, $V$. This drop in velocity correlates to an increase in the turbulence in the same region beside the guide wall. Second, the velocity component in the y-direction was shown to be negative in the upper portion of the water column and positive below the guide wall. This was expected as the guide wall was designed to create a strong sweeping velocity along the structure's face toward the bypass. Third, the minimum velocity in the z-direction (a negative value) occurs directly at the bottom of the guide wall. Fourth, the guide wall created a high velocity gradient along the z-axis at the face of the wall. Lastly, the velocity distribution beside and below the guide wall was very similar at each of the locations.

\subsection{Maximum to Mean Velocity Ratio (MMR)}

The $M M R$ was calculated as the ratio of the maximum velocity magnitude on a specified plane to the average inlet velocity magnitude $(V)$. The specified plane was on the $\mathrm{y}-\mathrm{z}$ axis at the longitudinal midpoint of the guide wall (where $x=0.5 L$ ) and extends from the water surface to the bottom of the guide wall. A value of the maximum velocity magnitude was determined for each of the 40 scenarios based on the CFD output and then divided by the average inlet velocity magnitude for the scenario. Fig. 5 shows the results in a contour plot for both $V=2 \mathrm{ft} / \mathrm{s}$ and $V=$ $4 \mathrm{ft} / \mathrm{s}$ for all 40 scenarios.

Interestingly, the average approach velocity had minimal impact on the $M M R$. The values under all configurations range from 1.14 to 1.62 , with the lowest for a guide wall design of $d=10 \mathrm{ft}$ and $\theta=15^{\circ}$ and the greatest for a design where $d=20 \mathrm{ft}$ and $\theta=45^{\circ}$. Also, recalling 
from Fig. 4, the maximum velocity magnitude occurs at the very bottom of the guide wall near the face of the wall. This was consistent throughout all 40 scenarios.

\subsection{Downward to Sweeping Velocity Ratio (DSR)}

A problematic feature of some guide walls tested to date was that they can create a strong downward flow component which can likely lead to a reduction in guidance efficiency. To evaluate this in the scenarios we tested, we formulated a metric that represented the Downward to Sweeping Velocity Ratio (DSR), or the ratio of the velocity in the z-direction to the magnitude of the $\mathrm{x}$ and $\mathrm{y}$ velocity components. To do this we assumed (based in part on the rheotactic behavior of fish) that the larger the absolute value of the $D S R$, the more likely a fish will be to volitionally follow the downward current or be entrained below the guide wall. The DSR at each cell of the model was calculated using the following formula:

$$
D S R=\frac{V_{z}}{\sqrt{V_{x}^{2}+V_{y}^{2}}}
$$

Where $V_{z}$ is the velocity in the z-direction, $V_{x}$ is the velocity in the x-direction, and $V_{y}$ is the velocity in the y-direction. The sweeping velocity (denominator of the $D S R$ ) at an elevation above the bottom of the guide wall was always in the direction of the bypass whereas the vertical velocity (numerator of the $D S R$ ) was always negative. Fig. 6 displays a $D S R$ contour plot on a vertical plane in the $y-z$ axis at the longitudinal midpoint of the guide wall $(x=0.5 L)$ for the scenario of $d=10 \mathrm{ft}, \theta=30^{\circ}$, and $V=2 \mathrm{ft} / \mathrm{s}$. A negative value indicates a downward flow, away from the water surface.

Fig. 6 shows a typical distribution of the $D S R$ taken at a plane at any x-location along the guide wall. There was a distinct $D S R$ gradient that occurs along the face of the guide wall in the z-direction where the values range from approximately 0 at the water surface to -0.825 at the bottom of the guide wall. This gradient exists for each scenario, consisting of a DSR of 
approximately 0 at the water surface and a minimum value, $D S R_{\min }$, occurring along the very bottom of the guide wall, although the minimum value changes depending upon the depth and angle of the structure. The location of $D S R_{\min }$ is the same location where the velocity magnitude reached its maximum value. Thus under this condition, a fish swimming along the bottom of the guide wall might be more likely to be entrained beneath it rather than safely guided to the bypass.

By finding $D S R_{\min }$ for each scenario, we were able to state if the worst-case conditions along the guide wall are sweeping dominant $\left(D S R_{\min }>-1.0\right)$ or downward dominant $\left(D S R_{\min }<-\right.$ 1.0). Therefore, in the case that $D S R_{\min }$ was greater than -1.0 , it was known that conditions from the water surface elevation (WSE) to the bottom of the guide wall were sweeping dominant. However, if $D S R_{\min }$ indicated that a specific scenario was downward dominant, then it was known that there was a transition point somewhere between the WSE and the bottom of the guide wall where the flow field shifts from sweeping dominant to downward dominant. This "transition depth" (later referred to as $d^{*}\left(t^{*}=-1\right)$ ) was investigated in the following sub-section (3.4).

Fig. 7 displays two contour plots (for $V=2 \mathrm{ft} / \mathrm{s}$ and $V=4 \mathrm{ft} / \mathrm{s}$ ) which illustrate how $D S R_{\min }$ changes depending upon the depth and angle of the structure. The values range from approximately $-0.4\left(d=10 \mathrm{ft}, \theta=15^{0}\right)$ to $-2.3\left(d=20 \mathrm{ft}, \theta=45^{0}\right)$.

\subsection{Upper Guidance Zone Depth $(d *)$}

Given a $D S R$ threshold value $\left(t^{*}\right)$, the guide wall can be split from the water surface elevation (WSE $=\mathrm{H}=40 \mathrm{ft}$ ) to the guide wall depth, $d$, into two separate zones. For a given $t^{*}$, the minimum depth (equivalent to the maximum elevation) at which the $D S R$ was equal to or less than $t^{*}$ is the Upper Guidance Zone Depth $\left(d^{*}\left(t^{*}\right)\right)$. For example, referring back to Fig. 6 and 
given a $t^{*}=-0.4, d^{*}\left(t^{*}=-0.4\right) \approx 7.5 \mathrm{ft}$. The volume above the elevation at depth $d^{*}\left(t^{*}\right)$

possessed a $D S R$ greater than $t^{*}$ and the volume below possessed a $D S R$ less than or equal to $t^{*}$. The metric was based on the hypothesis that, due to a guide walls tendency to create strong downward flows along its face, the guide wall can be split into an "Upper Guidance Zone" and a "Lower Guidance Zone". The Upper Guidance Zone was considered to be more likely to effectively guide fish because of its reduced absolute value of the DSR. The Lower Guidance Zone was considered to be less likely to effectively guide fish because of its greater absolute value of the DSR. Fig. 8 shows for $V=2 \mathrm{ft} / \mathrm{s}$ and $V=4 \mathrm{ft} / \mathrm{s}$ how the dependent variable $d^{*}\left(t^{*}\right)$ changes with the independent variable $t^{*}$. The minimum $d^{*}\left(t^{*}\right)$ is zero and the maximum is the depth of the guide wall, $d$.

The impact of changing the guide wall depth and angle on $d^{*}\left(t^{*}\right)$ is evident in Fig. 8. For instance, the value of $t^{*}$ where $d^{*}\left(t^{*}\right)$ equals guide wall depth, $d$, changes dramatically from 0.8145 for a guide wall design of $\theta=15^{\circ}$ and $d=20 \mathrm{ft}$. to -2.2715 for a guide wall design of $\theta=$ $45^{\circ}$ and $d=20 \mathrm{ft}$. This is also evident when changing the guide wall depth as $d^{*}\left(t^{*}\right)$ first equals $d$ ranging from -1.4965 to -2.2715 for guide wall designs where $\theta=45^{\circ}$. Note that when $d=$ $d^{*}\left(t^{*}\right)$ there was a $D S R$ greater than $t^{*}$ along the full depth of the guide wall.

Also of note was that $d^{*}\left(t^{*}\right)$ was nearly identical for each average inlet velocity. This implies that when calculating the $D S R$ a change in velocity within the power canal was much less important than the design parameters of the guide wall. However, the actual z-component of the velocity changes in response to the prescribed average inlet velocity, $V$.

Fig. 9 better illustrates the difference between $d^{*}\left(t^{*}\right)$ and $\mathrm{d}$ for all combinations of guide wall depths and angles with $V$ equal to $2 \mathrm{ft} / \mathrm{s}$ and $t^{*}$ equal to -1 (left), -0.67 (middle), and -0.33 
(right). The transition depth alluded to in the previous sub-section (3.4) is represented in the left contour plot.

Most noticeable from Fig. 9 is that the difference between the guide wall depth, $d$, and the Upper Guidance Zone Depth, $d^{*}$, increases as $t^{*}$ was reduced. This was expected as the threshold becomes more restrictive. This also shows the advantages of a lesser angle, particularly for the $t^{*}$ values closer to zero. For example, the difference in $d^{*}\left(t^{*}=-.33\right)$ for the scenario of $\theta=15^{\circ}$ and $d=20 \mathrm{ft}$. and the scenario of $\theta=45^{\circ}$ and $d=20 \mathrm{ft}$. was approximately 10 ft. This difference was half of the guide wall depth for those scenarios. For these same two scenarios the difference in $d^{*}\left(t^{*}=-1\right)$ was approximately $6 \mathrm{ft}$.

\section{Discussion \& Conclusion}

Considering the information gleaned from this study, a relatively small angle (the minimum was $15^{\circ}$ ) appears more likely to produce conditions favorable to efficient guidance. Both the metric related to the maximum velocity $(M M R)$ and the downward to sweeping velocity ratio $(D S R)$ show that as the angle was increased 1) smaller juvenile fish should be more likely to be entrained below the guide wall and 2) larger adult fish should be more likely to volitionally pass below the guide wall. Interestingly, lab-scale physical modeling performed by the California Department of Water Resources (CA DWR) found that guide wall panels oriented at 22 degrees to the flow and set at a depth of 5 feet resulted in neutrally buoyant beads guiding along and not passing under the guide wall (personal communication, Shane Scott, 3/14/14). Although this exact scenario was not tested in this analysis, it also shows the benefit of guide walls set at an angle near $15^{\circ}$.

However, such a small angle may not always be required. In general, the authors recommend that the guide wall be set at an angle and depth such that $d^{*}\left(t^{*}>-1\right)$ is greater than 
the maximum depth of the expected vertical distribution of all the target fish species at the site. The assumption of $t^{*}>-1$ was applied to ensure sweeping-dominant conditions and was designed to both take advantage of the negative rheotactic fish response and to guide any passively drifting juvenile fish. DSR threshold values closer to zero are likely to be more effective at reducing the number of fish that pass below the guide wall, although will require a longer (smaller angle) and/or deeper wall to achieve.

Without testing fish movement and behavior in response to guide walls in real-world applications, it is difficult to predict how a fish will respond to the flow conditions. Although generalized metrics partially based on the behavior known as rheotaxis were formulated, the results can in no way estimate actual fish behavior. Each of the metrics developed were based entirely on the velocity output data from the CFD analysis. Fish behavior was also impacted by hydraulic conditions such as acceleration and turbulence (Larinier, 1998), but fish also possess complex and unpredictable behaviors in response to environmental conditions both inclusive and exclusive of hydraulics. Therefore, the authors recognize that the inclusion of some of these variables in the evaluation of each scenario could make for a more sound approach to understanding how fish will behave near the guide wall.

Field studies of guide wall installations that include detailed telemetry analysis are uncommon. One such study (referenced in the Introduction Section) was performed at the Cowlitz Falls Dam in 2011 (Kock et al., 2012) using radiotelemetry to track juvenile salmonids. The guide wall was constructed of steel panels attached to a floating boom set at $10 \mathrm{ft}$. deep and approximately $45^{\circ}$ to the approach flow. The study found that 40 to $63 \%$ of the fish by species arrived at the fish collection discovery area (defined as the region around the downstream terminus of the guide wall). However, the movement patterns also showed that the fish had a 
strong tendency to sound under the wall and on to the turbine intakes where 33 to $52 \%$ of the fish by species passed downstream (the largest percentage of all the passage routes). Based on the CFD analysis in this manuscript, the $D S R_{\min }$ for a guide wall at this depth and angle is approximately -1.6 (see Fig. 7) and the transition depth, $d^{*}\left(t^{*}=-1.0\right)$, is between 8 and $9 \mathrm{ft}$ (see Fig. 9). It's likely that the guidance efficiency would have increased by either installing a deeper guide wall or lowering the angle.

CFD is based in physical laws and is capable of producing accurate and reliable results. Several other studies have been performed using CFD as a means to better understand how a guide wall will impact the flow field in a forebay (Rakowski et al., 2006; Rakowski et al., 2010; Lundstrom et al., 2010). Lundstrom et al. (2010) examined ten guide wall configurations (different lengths, curvatures, and depths) upstream of a spillway and turbine intakes at a hydroelectric facility. An important metric used in this analysis was the acceleration along the guide wall and the acceleration downward upstream of the guide wall. The authors argued that a high acceleration downward immediately upstream of the guide wall would improve guidance efficiencies juvenile fish tend to avoid regions of high acceleration (Haro et al.,1998; Kemp et al., 2005; Johnson et al., 2000; Taft, 2000). The authors were satisfied with the performance of the guide wall because the acceleration along the device was much smaller than that going downward, meaning the fish would choose the route along the device. While this may be true in certain cases, we argue caution because a downward acceleration that is too high may entrain the weak swimming juvenile fish and force them under the wall towards the turbines.

Furthermore, the authors acknowledge several limitations to this study. First, the selected model domain of a rectangular power canal was not truly representative of a real hydropower project, which likely has much more complex hydraulics. When possible in practice, the authors 
recommend applying the derived metrics to a site-specific CFD model in order to determine proper depths and angle. Second, the use of a single phase model results in a loss of model resolution near the water surface boundary layer, although this is not expected to make a substantial difference in the results and is a common simplification when wave action is not integral in the analysis. Third, physical aspects of the structure have been ignored. The forces applied to a guide wall may create a vertical tilt such that the guidance wall is not perpendicular to the water surface and/or a curvature may develop when looking from plan view. Ideally, strengthening of the structure and anchoring it to the bottom could minimize the deflection. More research is needed to investigate the hydraulics of tilted/deflected guide walls.

In conclusion, guide walls have been utilized to improve downstream passage survival for anadromous fishes including salmonids and alosines for more than 20 years. Less frequently implemented than other surface guidance technologies (e.g. louvers, bar racks, screens, among others), they are gaining popularity, particularly in the northwestern United States. This body of research focuses on the basic design parameters and begins to answer the question of which configuration might enhance fish guidance. A CFD approach was used to answer this fundamental question. The key findings indicated that a guide wall set at a small angle and deep enough such that sweeping-dominant conditions (or $d^{*}\left(t^{*}>-1\right)$ ) covers the expected vertical distribution of the approaching fish was more likely to produce hydraulics favorable for efficient guidance. Future work is necessary, particularly to investigate other guide walls configurations and perform more rigorous full-scale, field tests with the various fish species of interest.

\section{Acknowledgments}

The information, data, or work presented herein was funded in part by the Office of Energy Efficiency and Renewable Energy (EERE), U.S. Department of Energy, under Award Number 
DE-EE0002668 and the Hydro Research Foundation. In addition, this work was partly funded by the Perrell family who generously offered support in the first author's final semester at the University of Massachusetts.

\section{Disclaimer}

The information, data or work presented herein was funded in part by an agency of the United States Government. Neither the United States Government nor any agency thereof, nor any of their employees, makes and warranty, express or implied, or assumes any legal liability or responsibility for the accuracy, completeness, or usefulness of any information, apparatus, product, or process disclosed, or represents that its use would not infringe privately owned rights. Reference herein to any specific commercial product, process, or service by trade name, trademark, manufacturer, or otherwise does not necessarily constitute or imply its endorsement, recommendation or favoring by the United States Government or any agency thereof. The views and opinions of authors expressed herein do not necessarily state or reflect those of the United States Government or any agency thereof. 


\section{Notation}

The following symbols are used in this paper:

$d=$ Guide wall depth (ft.)

$d^{*}\left(t^{*}\right)=$ Upper Guidance Zone depth (ft.)

$D S R=$ Downward to sweeping velocity ratio (-)

$D S R_{\min }=$ Minimum downward to sweeping velocity ratio at each cross-section (-)

$\mathrm{H}=$ Water depth (ft.)

$\ell=$ Approach distance (ft.)

$L=$ Distance along the $\mathrm{x}$-axis from the upstream to downstream ends of the guide wall (ft.)

$M M R=$ Maximum to mean velocity ratio (-)

$\mathrm{p}=$ Percent of the flow through the bypass relative to the flow through the model inlet $(\%)$

$Q_{B}=$ Total flow rate into bypass $\left(\mathrm{ft}^{3} / \mathrm{s}\right)$

$Q_{C}=$ Total flow rate under guide wall $\left(\mathrm{ft}^{3} / \mathrm{s}\right)$

$Q_{T}=$ Total flow rate through model inlet $\left(\mathrm{ft}^{3} / \mathrm{s}\right)$

$t^{*}=$ Downward to sweeping velocity ratio threshold (-)

$V=$ Average approach velocity $(\mathrm{ft} / \mathrm{s})$

$V_{x}=$ Mean velocity in the $\mathrm{x}$-direction $(\mathrm{ft} / \mathrm{s})$

$V_{y}=$ Mean velocity in the y-direction $(\mathrm{ft} / \mathrm{s})$

$V_{z}=$ Mean velocity in the z-direction $(\mathrm{ft} / \mathrm{s})$

$\mathrm{W}=$ Channel width (ft.)

$\theta=$ Angle of the guide wall relative to the side wall of the power canal (degrees) 


\section{References}

ANSYS, Inc. (2012). ANSYS FLUENT theory guide. Canonsburg, PA: Southpointe.

Buckley, J., \& Kynard, B. (1985). Vertical distribution of juvenile American Shad and Blueback Herring during the seaward migration in the Connecticut River. Massachusetts Cooperative Fishery Research Unit, Department of Forestry and Wildlife Management, Amherst, MA.

Bunt, C. M., Castro-Santos, T., \& Haro, A. (2012). Performance of fish passage structures at upstream barriers to migration. River Research and Applications, 28, 457-178. doi: 10.1002/rra.1565

Enders, E. C., Gessel, M. H., \& Williams, J. G. (2009). Development of successful fish passage structures for downstream migrants requires knowledge of their behavioural response to accelerating flow. Canadian Journal of Fisheries and Aquatic Sciences, 66, 2109-2117. doi:10.1139/F09-141

Faber, D. M., Ploskey, G. R., Weiland, M. A., Deng, D., Hughes, J. S., Kim, J., Fu, T., Fischer, E.S., Monter, T.J., \& Skalski, J. R. (2011). Evaluation of behavioral guidance structure on juvenile salmonid passage and survival at Bonneville Dam in 2009. Richland, WA: Pacific Northwest National Laboratory.

Haro, A., Odeh, M., Noreika, J., \& Castro-Santos, J. (1998). Effect of water acceleration on downstream migratory behavior and passage of Atlantic salmon juvenile salmonids and juvenile American shad at surface bypasses. Transactions of the American Fisheries Society, 127, 118-127.

Johnson, G. E., \& Dauble, D. D. (2006). Surface flow outlets to protect juvenile salmonids passing through hydropower dams. Reviews in Fisheries Science, 14, 213-244. 
Johnson, G. E., Adams, N. S., Johnson, R. L., Rondorf, D. W., Dauble, D. D., \& Barila, T. Y. (2000). Evaluation of the prototype surface bypass for salmonid juvenile salmonids in spring 1996 and 1997 at Lower Granite Dam on the Snake River, Washington.

Transactions of the American Fisheries Society, 129, 381-397.

Johnson, G. E., Giorgi, A. E., \& Erho, M. W. (1997). Critical assessment of surface flow bypass development in the lower Columbia and Snake rivers. Completion Report for the U.S. Army Corps of Engineers, Portland and Walla Walla Districts.

Kemp, P. S., Gessel, M. H., \& Williams, J. G. (2005). Fine-scale behavior responses of pacific salmonid smolts as they encounter divergence and accleration of flow. Transactions of the American Fisheries Society, 134(2), 390-398.

Kock, T. J., Liedtke, T. L., Ekstrom, B. K., Tomka, R. G., \& Rondorf, D. W. (2012). Behavior and passage of juvenile salmonids during the evaluation of a behavioral guidance structure at Cowlitz Falls Dam, Washington, 2011. U.S. Geological Survey Open-File Report 2012-1030.

Larinier, M. (1998). Upstream and downstream fish passage experience in France, In: Fish Migration and Fish Bypasses. 127-145. (M. Jungwirth, S. Schmutz, \& S. Weiss, Eds.) Blackwell Science Ltd Publisher.

Limburg, K. E., \& Waldman, J. R. (2009). Dramatic declines in North Atlantic diadromous fishes. BioScience, 59(11), 955-965. doi:10.1525/bio.2009.59.11.7

Lundstrom, T. S., Gunnar, J., Hellstrom, I., \& Lindmark, E. M. (2010). Flow design of guiding device for downstream fish migration. River Research and Applications, 26, 166-182.

Weiss-Glanz, L. S., Stanley, J. G., \& Moring, J. R. (1986). Species profiles: life histories and environmental requirements of coastal fishes and invertebrates (North Atlantic): 
American shad. U.S. Fish and Wildlife Service Biological Report 82(11.59). U.S. Army Corps of Engineers, TR EL-82-4. 16 pp.

McDowall, R. M. (1987). Evolution and importance of diadromy. American Fisheries Society Symposium, 1, 1-13.

McDowall, R. M. (1997). The evolution of diadromy in fishes (revisited) and its place in phylogenetic analysis. Reviews in Fish Biology and Fisheries, 7, 443-462.

NextEra Energy Maine Operating Services, LLC. (2010). NextEra Energy diadromous fish passage report for the Lower Kennebec River watershed during the 2009 migration season. Hallowell, ME.

Odeh, M., \& Orvis, C. (1998). Downstream fish passage design considerations and developments at hydroelectric projects in the Northeast USA. In M. Jungwirth, S. Schmutz, \& S. Weiss (Eds.), Fish Migration and Fish Bypasses (pp. 267-280). Oxford, UK: Fishing New Books.

Patankar, S.V. \& Spalding, D.B. (1972). A calculation procedure for heat, mass and momentum transfer in three-dimensional parabolic flows. Int. J. Heat Mass Transfer, 15, 1787-1806

Rakowski, C. L., Richmond, M. C., Serkowski, J. A., \& Johnson, G. E. (2006). Forebay computational fluid dynamics modeling for the Dalles Dam to support behavior guidance system siting studies. Final Report. Prepared for the U.S. Army Corps of Engineers Portland District, Portland, Oregon Under a Related Services Agreement with the U.S. Department of Energy Contract DE-AC06-76RL01830.

Rakowski, C. L., Richmond, M. C., \& Serkowski, J. A. (2010). Bonneville Powerhouse 2 3D CFD for the Behavioral Guidance System. Prepared for the U.S. Army Corps of 
Engineers Portland District, Portland, Oregon Under a Contract DE-AC05-76RL01830 with the U.S. Department of Energy.

Schilt, C. R. (2007). Developing fish passage and protection at hydropower dams. Applied Animal Behaviour Science, 104, 295-325. doi:10.1016/j.applanim.2006.09.004

Scott, S. (2012). A postive barrier fish guidance system designed to improve safe downstream passage of anadromous fish. 9th ISE 2012. Vienna.

Taft, E. P. (2000). Fish protection technologies: a status report. Environmental Science Policy, 3, 5349-5359.

Whitney, R., Calvin, L., Erho, M., \& Coutant, C. (1997). Downstream passage for salmon at hydroelectric projects in the Columbia River basin: development, installation, and evaluation. Portland, OR: Northwest Power Planning Council.

Williams, J. G., Armstrong, G., Katopodis, C., Larinier, M., \& Travade, F. (2012). Thinking like a fish: A key ingredient for development of effective fish passage facilities at river obstructions. River Res. Applic., 28, 407-417. doi:10.1002/rra.1551 

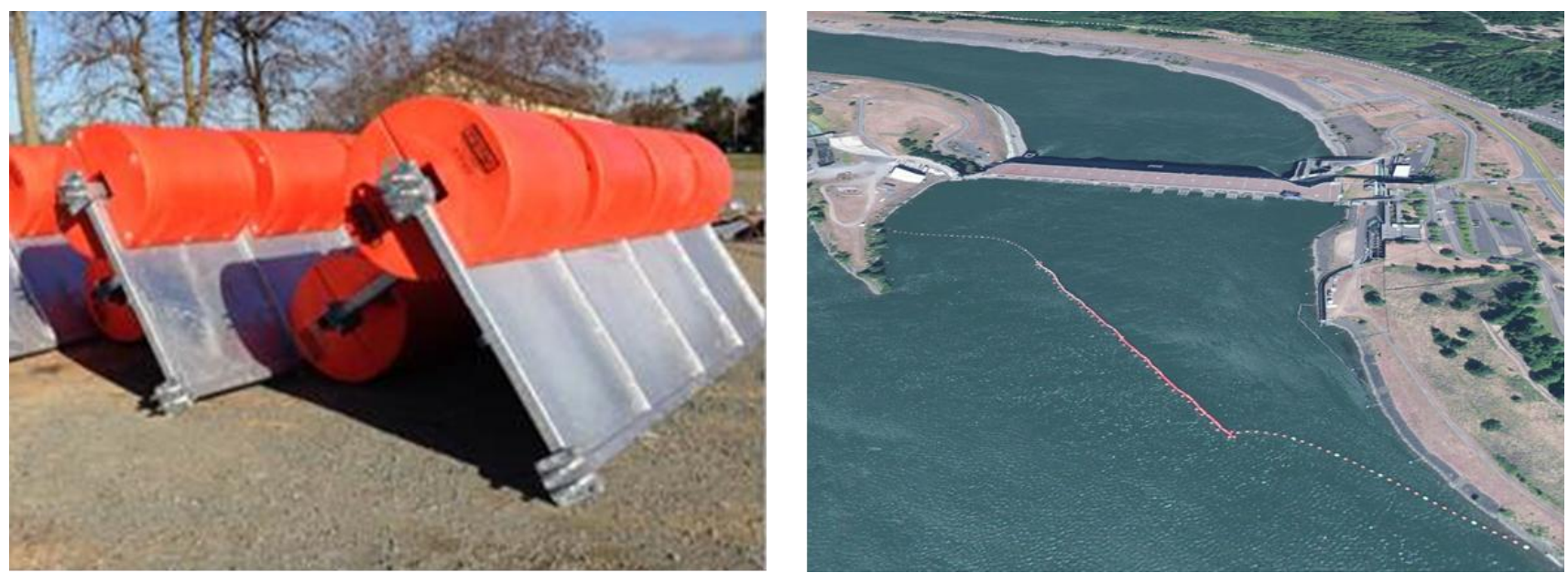

Figure 1: Partial-depth, floating, guide wall. The photo on the left (provided by Shane Scott) shows the panels with the floating boom. The photo on the right (taken from Google Earth) shows an installed guidance device at the Bonneville Dam. 


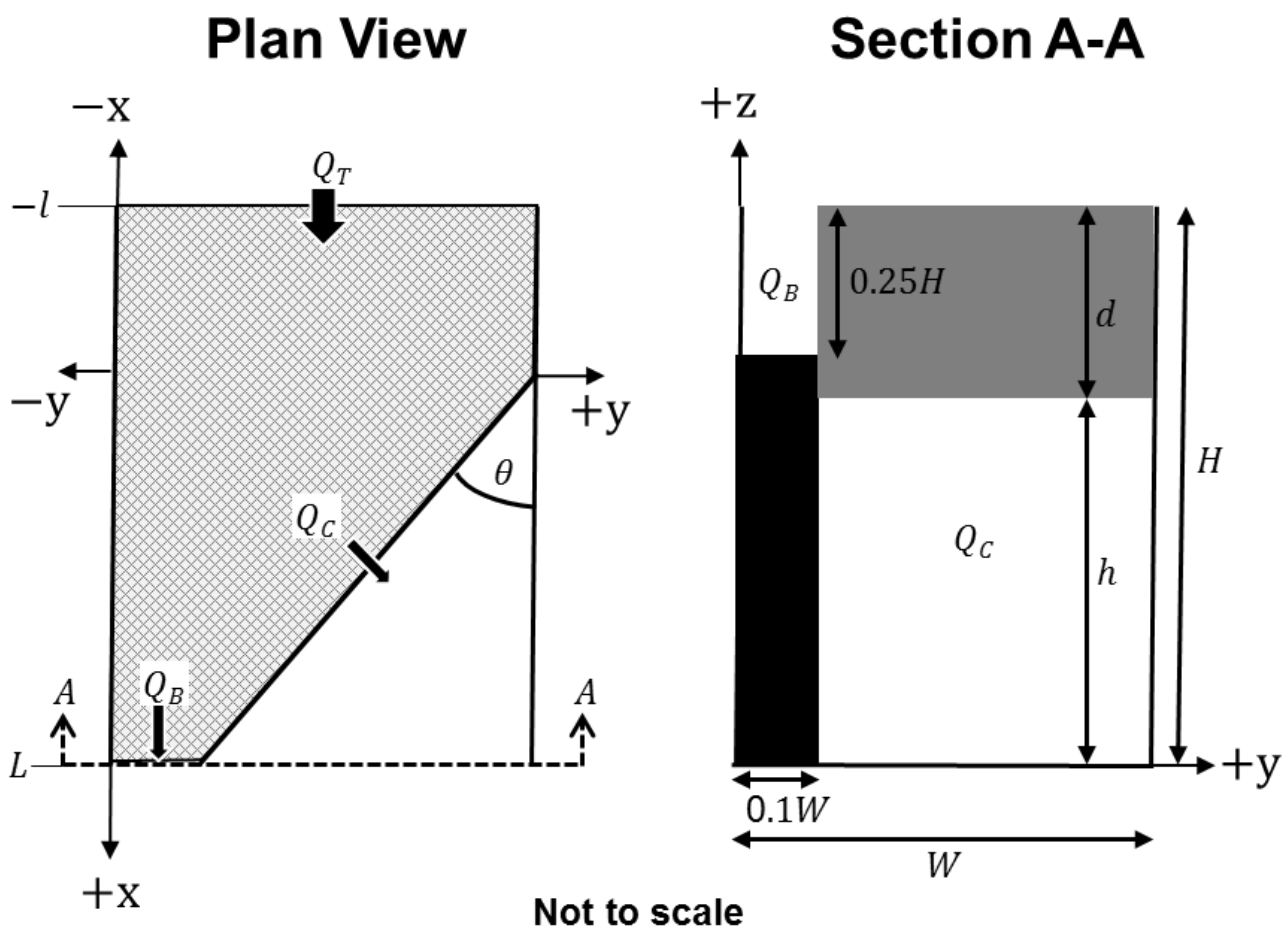

Figure 2: The schematic on the left shows the plan view of the idealized power canal. The hatched area (upstream of the guide wall and bypass entrance) is the modeled region. The schematic on the right shows the cross-sectional view from $\mathrm{A}-\mathrm{A}$, the furthest downstream location as seen on the plan view. The grey area is the guide wall. The black area is the wall directly below the bypass entrance. Note the $x-y-z$ axis, the intersection of the $x$ and $y$ axis always occurs at the most upstream section of the guide wall, as shown above. On the $x$-axis, the bypass outlet is located at $x=L$ and the model inlet is located at $x=-l$. 
Velocity Magnitude (ft/s)

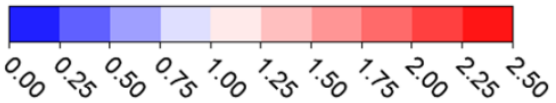

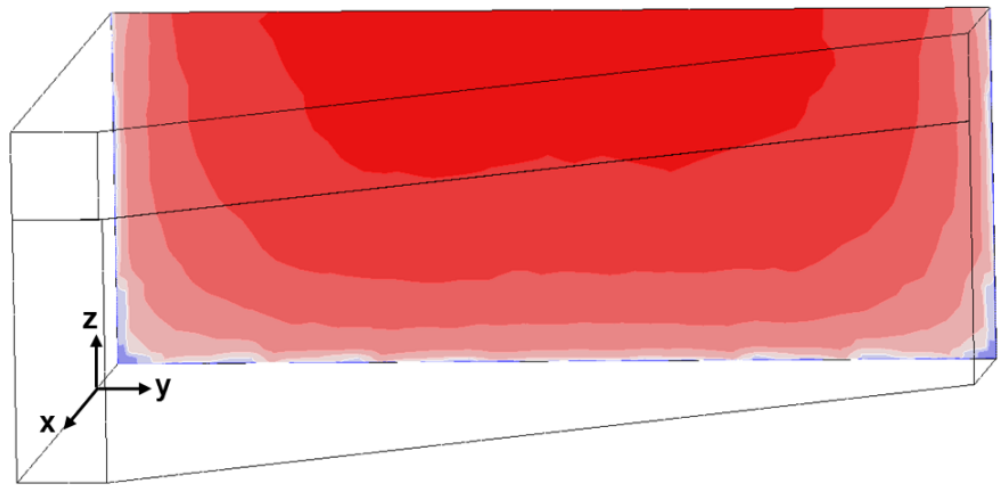

Figure 3: The contour plot on the inlet of the CFD model geometry represents the velocity specified as a boundary condition in the case of $V=2 \mathrm{ft} / \mathrm{s}$. Note the fully developed flow profile. Flow is in the positive $x$-direction. The model domain is indicated by the black outline in this 3-D view. 
Scenario: $d=10 \mathrm{ft}, \theta=30^{\circ}, V=2 \mathrm{ft} / \mathrm{s}$

$\begin{array}{cccc}\text { Velocity } & \text { Velocity } & \text { Velocity } & \text { Velocity } \\ \text { Magnitude (ft/s) } & \text { X-direction (ft/s) } & \text { Y-direction (ft/s) } & \text { Z-direction (ft/s) }\end{array}$

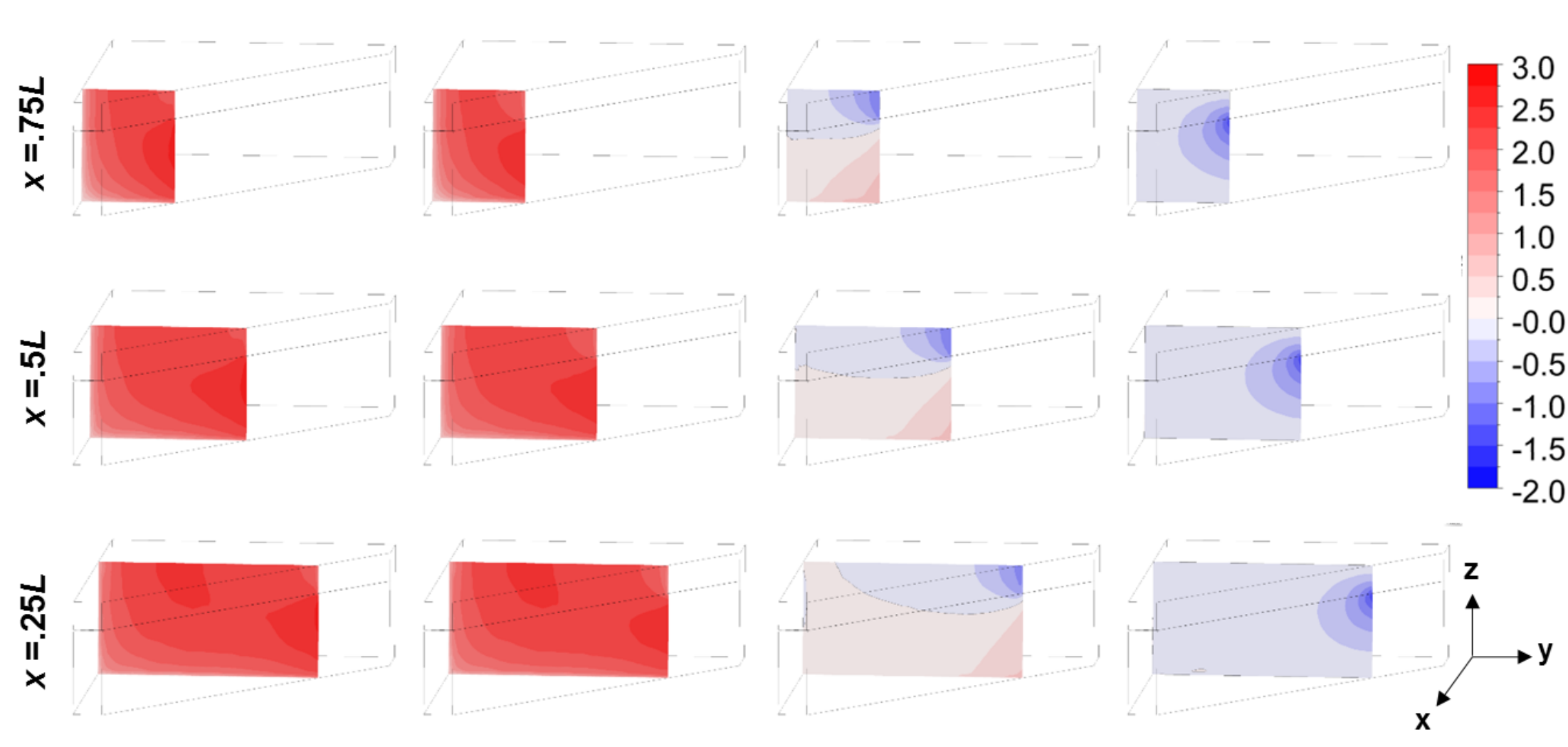

Figure 4: Contour plots of the velocity magnitude (far left), velocity in the $x$-direction (mid-left), velocity in the $y$-direction (mid-right), and velocity in the z-direction (far right) for the scenario of $d=10 \mathrm{ft}, \theta=30^{\circ}$, and $V=2 \mathrm{ft} / \mathrm{s}$. The top row plots are for a plane located at $x=.75 \mathrm{~L}$. The middle row plots are for a plane located at $x=.5 \mathrm{~L}$. The bottom row plots are for a plane located at $x=.25 \mathrm{~L}$. 

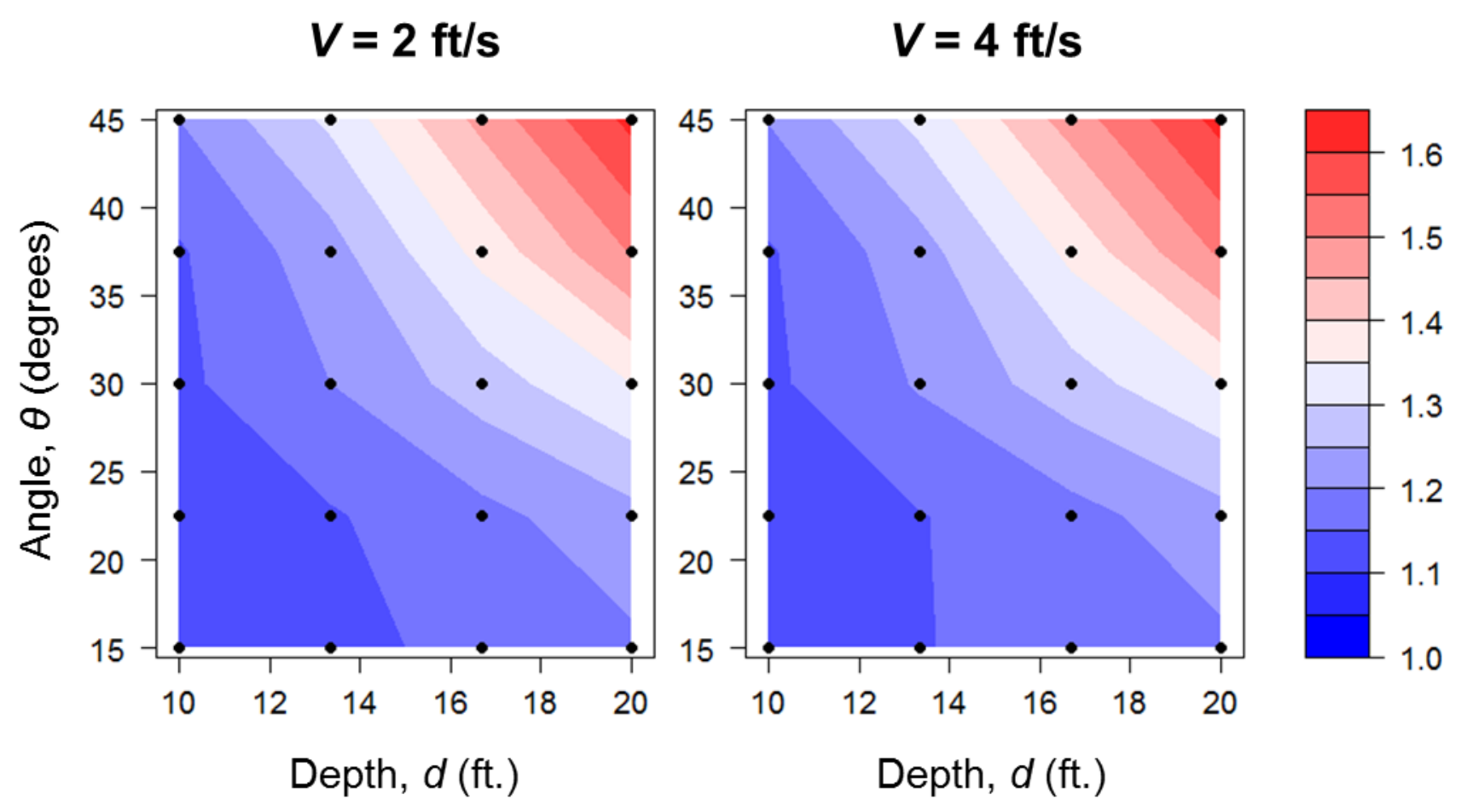

Figure 5: Contour plots of the Maximum to Mean Velocity Ratio (MMR) for $V=2 \mathrm{ft} / \mathrm{s}$ (left) and $V=4 \mathrm{ft} / \mathrm{s}$ (right). The guide wall depth, $d$, is on the $\mathrm{x}$-axis and the guide wall angle, $\theta$, is on the $y$-axis. The black circles indicate the data point locations corresponding to each combination of depth and angle run in the CFD analysis. The contour lines are the result of a linear interpolation between data points. 


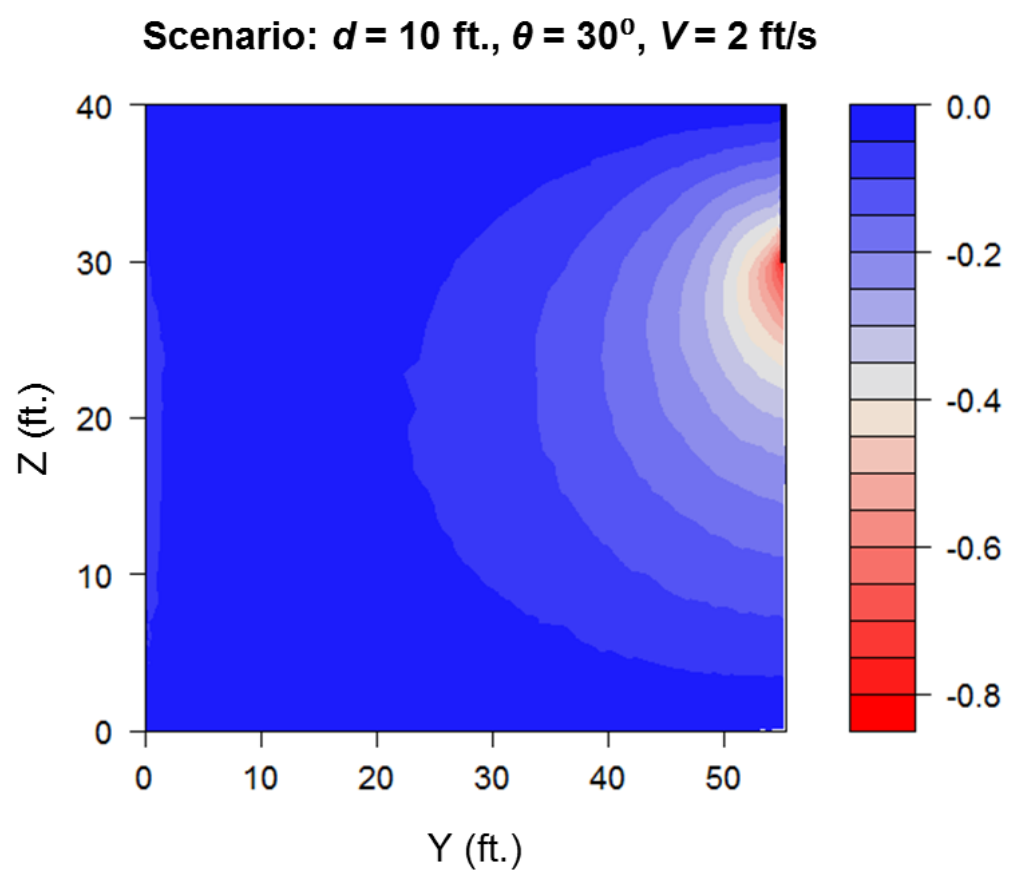

Figure 6: A contour plot of the $D S R$ for the scenario of $d=10 \mathrm{ft}, \theta=30^{\circ}$, and $V=2 \mathrm{ft} / \mathrm{s}$ taken at the longitudinal midpoint of the guide wall $(x=.5 L)$ on a vertical plane in the $y-z$ axis. The black rectangle in the top right indicates the location of the guide wall. Recall the WSE $=40 \mathrm{ft}$. 


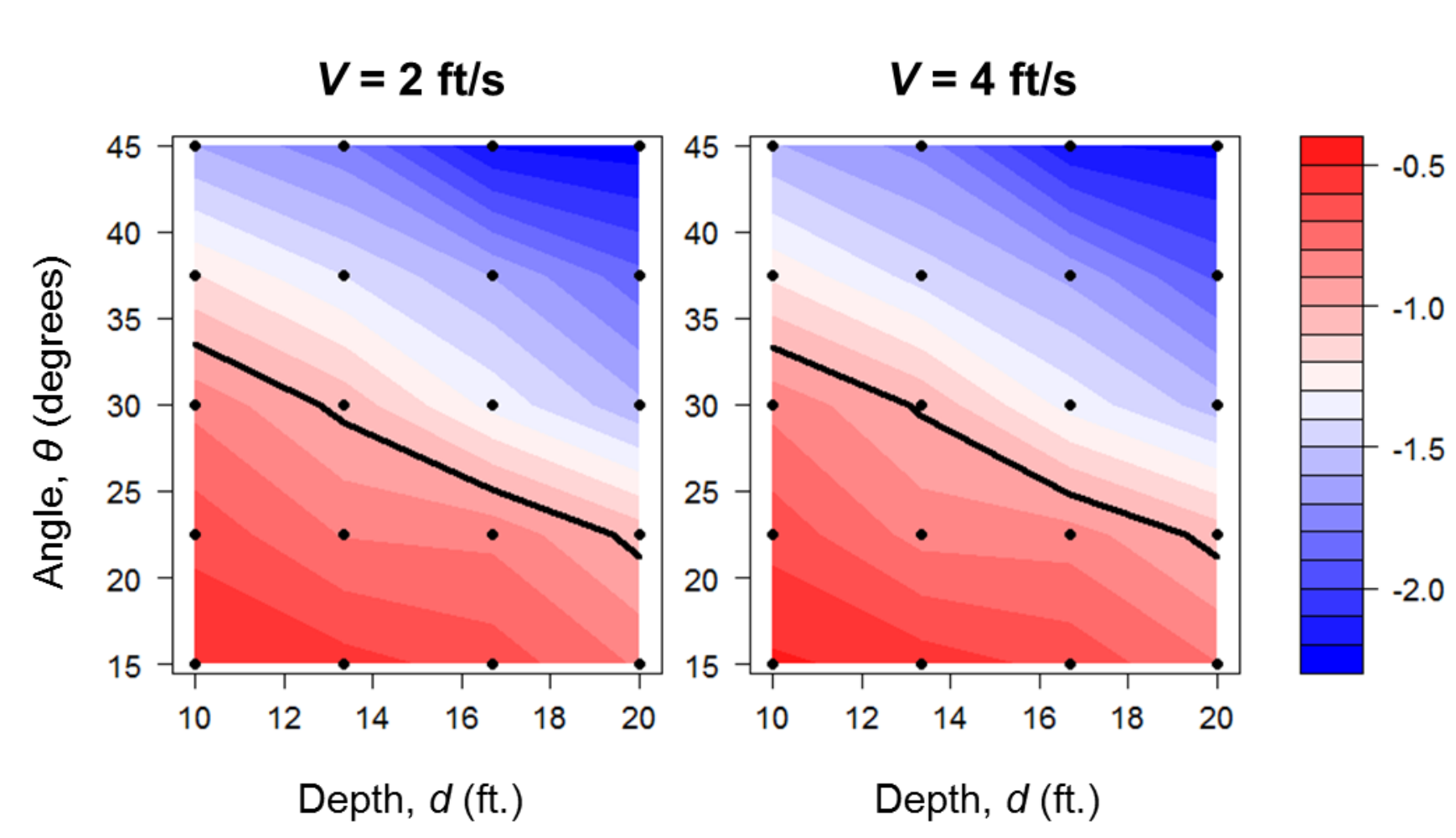

Figure 7: Contour plots of $D S R_{\min }$ for $V=2 \mathrm{ft} / \mathrm{s}$ (left) and $V=4 \mathrm{ft} / \mathrm{s}$ (right). The guide wall depth, $d$, is on the $x$-axis and the guide wall angle, $\theta$, is on the $y$-axis. The black circles indicate the data point locations, corresponding to each combination of depth and angle run in the CFD analysis. The black solid line is the contour where $D S R_{\min }=\mathbf{- 1 . 0}$. Scenarios above the line possess a sweeping dominant flow field along the entire depth of the guide wall whereas scenarios below the line possess a lower section of the guide wall where a downward dominant flow field exists. The contour lines are the result of a linear interpolation between data points. 

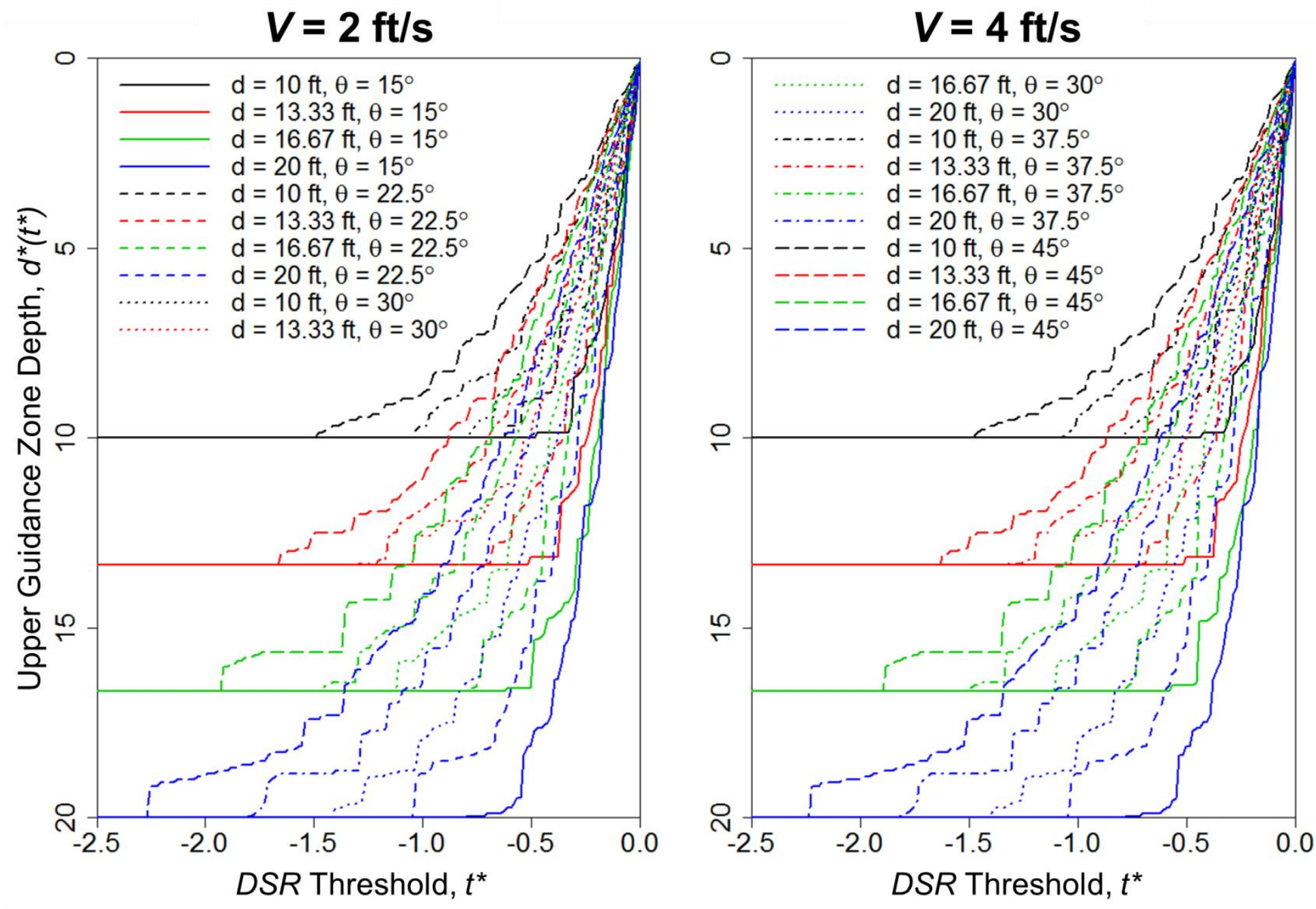

Figure 8: Plots of $d^{*}\left(t^{*}\right)$ versus the $D S R$ Threshold, $t^{*}$, for $V=2 \mathrm{ft} / \mathrm{s}$ (left) and $V=4 \mathrm{ft} / \mathrm{s}$ (right). 

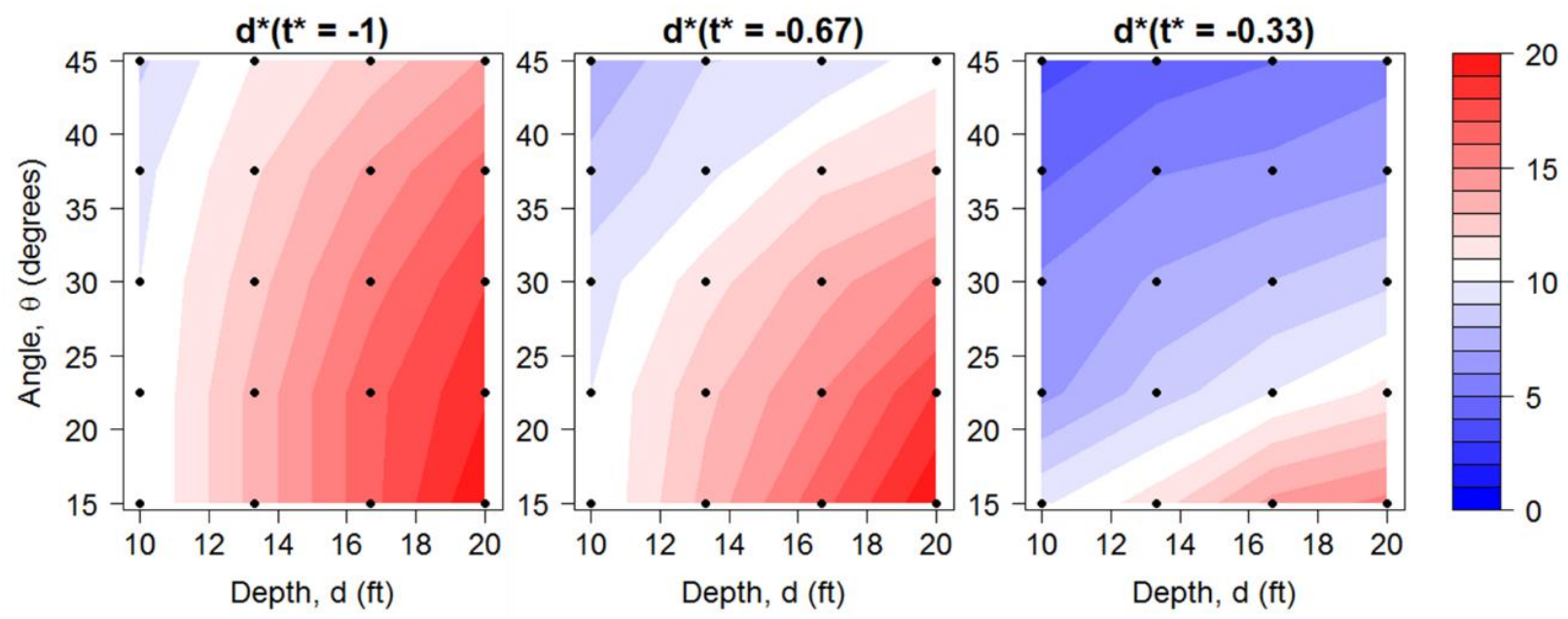

Figure 9: Contour plots of the Upper Guidance Zone Depth, $d^{*}\left(t^{*}\right)$ for $t^{*}=\mathbf{- 1 . 0}$ (left), $t^{*}=\mathbf{- 0 . 6 7}$ (middle), and $t^{*}=\mathbf{- 0 . 3 3}$ (right). The guide wall depth, $d$, is on the $x$-axis and the guide wall angle, $\theta$, is on the $y$-axis. The average inlet velocity, $V$, is equal to $2 \mathrm{ft} / \mathrm{s}$. The black circles indicate the data point locations, corresponding to each combination of depth and angle run in the CFD analysis. The contour lines are the result of a linear interpolation between data points. 